\title{
1. Climate-resilient development: an introduction
}

\section{Sam Fankhauser and Thomas K.J. McDermott}

\subsection{INTRODUCTION}

This book is about the link between economic development and adaptation to climate change from an economics perspective. Stern (2015) has called climate change and poverty alleviation the two biggest societal challenges of the twenty-first century. They are linked, Stern observes, and failing in one means failing in the other. The notion of climate-resilient development acknowledges this complementarity.

Low-income countries will be among the most affected by climate change, to the point where development progress might be at risk. At the same time, the rapid development these countries are undergoing - in terms of economic growth, capital accumulation and demographics - is changing fundamentally their vulnerability to climate change, for better or for ill. The combination of rapid population growth with ongoing urbanization, for example, is expected to lead to a large-scale expansion of urban areas, a trend that is most pronounced in locations that are vulnerable to climate extremes.

The pace and scale of changes underway means that the greatest opportunities for achieving climate resilience lie in guiding current development trends. This is reinforced by the danger - if climate risks are ignored - of locking in long-term risks, for example, through haphazard urban development in risky locations. There is a window of opportunity to act now to reduce future vulnerability.

The dynamic interaction of development trends with climate exposure and vulnerability is at the heart of climate-resilient development, and in contrast to traditional adaptation analysis. Much of the economic literature still treats adaptation to climate change as a set of self-standing activities that are assessed at the micro-level, for example, through cost-benefit analyses of specific response options. This often includes a fairly sophisticated treatment of climate scenarios and uncertainties, but little discussion of macro-level trends such as urbanization, economic diversification and openness to trade. 
Climate-resilient development is just one aspect of the broader notion of climate-smart development, which puts equal weight on reducing greenhouse gas emissions and managing residual climate risks. Even broader are the concepts of green growth - defined as growth that preserves aggregate natural capital (Bowen and Hepburn, 2014) - and sustainable development, which has an economic, social and environmental dimension (for an early definition see Pearce et al., 1989). It is important to take a holistic approach to development that encompasses all these concerns. However, there is also value in exploring in more depth the narrower challenge of climate-resilient development. That is the purpose of this book.

\subsection{FROM ADAPTATION TO CLIMATE-RESILIENT DEVELOPMENT}

Climate-resilient development both builds on and departs from traditional adaptation economics. To understand how it is worth reviewing how the economic analysis of adaptation has evolved over time.

Initially, the main objective of economic adaptation studies was to refine the understanding of climate change impacts. It was recognized that, to be accurate, climate change impact assessments had to factor in people's response to that change. As it was put at the time, farmers were not dumb (Schneider et al., 2000). They would adjust farming practices in response to new climate conditions. Similarly, coastal planners would adjust sea defences and households would increase air conditioning demand, all of which would alter the profile of climate change impacts. The insight was brought to its logical conclusion in the Ricardian approach to impact assessment (the pioneering paper is Mendelsohn et al., 1994). Ricardian studies compare the economic performance of well-adapted societies with different climates. That is, they assume a level of near-perfect adaptation. In reality, of course, farmers are neither dumb nor capable of adapting perfectly overnight. Adaptation requires forethought and effort.

The recognition that adaptation requires forethought turned it into an interesting economic problem in its own right. Researchers began to explore in normative terms how good adaptation decisions should look, particularly when dealing with climate uncertainty (Ranger et al., 2010; Hallegatte et al., 2011), and they developed prescriptions about who should do what and when (Fankhauser et al., 1999; Hallegatte et al., 2010).

Positive analysis explored why adaptation may be sub-optimal as a consequence of market, policy or behavioural barriers (Repetto, 2008; Cimato and Mullan, 2010) or more generally a lack in adaptive capacity (Brooks et al., 2005). Classifications were developed to better understand 
and describe the various forms of adaptation (Füssel, 2007). There was a suspicion, later corroborated by empirical evidence (for example, Tol and Yohe, 2007), that adaptation constraints were particularly prevalent in developing countries. This became known as the adaptation gap and effort went into understanding its causes (Fankhauser and McDermott, 2014).

An important question throughout was how much adaptation might cost (Fankhauser, 2010) and how the incremental cost of adaptation might be disentangled from baseline costs (Callaway et al., 2006). This was because developed countries had promised to support the adaptation efforts of poor countries under the United Nations Framework Convention on Climate Change. Negotiators wanted to know the size of the bill.

In all these research efforts, adaptation to climate change was treated as a distinct new challenge, a problem that had not existed before. Yet, adaptation to climatic risks is not a new problem. It is intricately linked to long-standing challenges, such as disaster risk management, water management, coastal zone planning, crop choices and infrastructure design. The climate context has always been crucial to these decisions. It is more useful therefore to think of climate change as adding further complexity to existing problems, instead of treating adaptation as a field in its own right.

One of the strongest links to existing challenges is between climate change and economic development. Adaptation and development are so heavily intertwined that in most practical cases it is not possible to ascertain where development interventions end and adaptation to climate change begins (McGray et al., 2007). Education, sanitation, good institutions and access to credit are core concerns of economic development. They are also important determinants of people's ability to deal with climate risks (Kahn, 2005; Tol and Yohe, 2007; McDermott et al., 2014).

This then is the basic tenet of climate-resilient development: to treat development and adaptation as heavily interrelated problems and to pursue poverty alleviation and climate resilience in an integrated way.

\subsection{THE LINKS BETWEEN CLIMATE AND DEVELOPMENT}

How does climate-resilient development differ from conventional development? Schelling $(1992,1997)$ famously claimed that economic development was the best form of adaptation, implying that conventional and climate-resilient development is one and the same. Yet not all forms of development have the same outcome in terms of climate resilience. There are important differences (Bowen et al., 2012). To identify them it is useful to revisit the main inter-linkages between climate and development. 
For many linkages the causality runs from climate to development. The main impacts of climate change on development are summarized by David Castells-Quintana, Maria Lopez-Uribe and Thomas K.J. McDermott in Chapter 2 and reviewed in more detail by the Intergovernmental Panel on Climate Change (IPCC, 2014). Climatic factors have a direct impact on development through agriculture and labour productivity, through the prevalence of disease and through the impact of weather extremes on physical and human capital. Less tangibly, and less well understood, climate factors may also affect development indirectly through their effect on institutions. In Chapter 3, Stephane Hallegatte, Mook Bangalore and coauthors outline the implications of climate change for poverty alleviation.

Most impact studies concentrate on level effects, such as a climate change-induced reduction in agricultural output, but these static effects have dynamic repercussions. There is evidence that, at least in developing countries, climate extremes are associated not just with lower economic output, but also with lower rates of growth (Dell et al., 2012). Growth rates are affected in a number of ways (Fankhauser and Tol, 2005). A reduction in economic output will translate into lower levels of investment, in absolute terms, and therefore slower capital accumulation and growth. Forward-looking agents may also change their savings behaviour if future returns on investment are at risk from climate change. In a world where growth is endogenous, these two effects may be exacerbated through changes in labour productivity and the rate of technical progress.

For other linkages the causality runs the other way round, from development trends to climate vulnerability. Many development choices have the potential to fundamentally alter the vulnerability profile of countries to climate change. Contrary to Schelling's $(1992,1997)$ conjecture, not all of these changes are necessarily positive.

As countries develop, many things change. The structure of their economy evolves, typically away from agriculture into industry and ultimately services. Across the economy, sectors become more productive as firms invest in modern technology and adopt new production techniques. The location of economic activity also shifts. This is often associated with migration away from rural areas and into the urban centres (Vivid Economics, 2015). Finally, income per capita rises. With higher incomes, the demand for climate protection also goes up. People invest more in adaptation (Fankhauser and McDermott, 2014).

Of these changes, only the increased demand for adaptation unequivocally reduces climate change risks. The net effect of the other trends is unclear. Although agriculture is highly sensitive to climate change, a structural shift into services and industry is beneficial only if those sectors are not themselves subject to climate risks. They may well be, for example, if 
production facilities are located in hazard zones, if water-intensive industries add to water stress or if firms are linked to vulnerable sectors through their supply chain (ASC, 2014). A similar story holds for structural shifts from outdoor activity (for example, agriculture, construction) to indoor occupations (manufacturing, services) and for rural-urban migration. The growth of coastal cities in Asia, for example, is associated with a massive increase in flood risk exposure (Hanson et al., 2011).

The impact of development trends on climate resilience is therefore ambiguous and context-specific. However, this means that it can at least in part be managed. By incorporating climate change concerns explicitly into development strategies, spatial plans and infrastructure decisions it is possible to anticipate and reduce future climate risks. This integrated, proactive approach to adaptation is the essence of climate-resilient development. There is much uncertainty about the specific nature of climate change impacts at the local level, but this does not imply a wait-and-see approach to adaptation planning, as discussed in the next section.

\subsection{ENSURING CLIMATE-RESILIENT DEVELOPMENT}

Climate-resilient development requires intervention on a number of fronts. Much of it will be carried out by private agents, but some of it must be spearheaded by government. In Chapter 4 David Castells-Quintana, Maria Lopez-Uribe and Thomas K.J. McDermott review the basic response strategies available to decision makers. The chapter distinguishes between in situ adaptation, which aims to make existing locations, livelihoods and forms of production less vulnerable, and transformational adaptation, which involves the movement of people and economic activity across sectors and across space.

Not all measures need to be implemented at once. In Chapter 7, Paul Watkiss identifies three generic priority areas, where adaptation action is required now: (1) strategic decisions with a long time horizon, such as spatial or urban settlement planning, which lock in vulnerability profiles for the long term; (2) low-regrets measures that have an immediate development impact as well as climate-resilience benefits; and (3) measures with long lead-times, such as research and development, which take time to come to fruition. The three priorities go back to a theoretical framework developed in Fankhauser et al. (1999), which recognizes the long-term, sequential nature of climate-resilient development (Box 1.1).

It makes sense to address climate change concerns in lockstep with conventional development planning. Development strategies typically have a 


\section{BOX 1.1 SETTING PRIORITIES FOR CLIMATE-RESILIENT DEVELOPMENT}

Ensuring climate resilience is a long process that will span over decades as climatic changes become increasingly evident. This raises the question of how response measures should be sequenced and timed.

From an economic point of view, an adaptation response should be fast-tracked if the net present value of implementing the measure now is greater than the net present value of implementing it later.

In simple mathematical notation, the net present value (NPV) of implementing a measure now can be written as follows:

$$
N P V^{\text {now }}=- \text { Cost }^{\text {now }}+S T_{-} \text {Benefit }{ }^{\text {now }}+\delta \cdot L T \_ \text {Benefit }{ }^{\text {now }}
$$

The net present value is the discounted sum of capital costs (which occur now), short-term benefits (also occurring now) and long-term benefits (which occur later and are therefore discounted at rate $\sigma$ ). For simplicity, we assume there are only two time periods, 'now' and 'later'.

We can compare this net present value to the NPV of implementing the same measure at a later date:

$$
N P V^{\text {later }}=-\delta \cdot \text { Cost }^{\text {later }}+\delta \cdot L T_{-} \text {Benefit }{ }^{\text {later }}
$$

Capital costs now occur in the later period and therefore have to be discounted. Although the proposed measure is the same, future costs may differ, for example, because retrofitting a measure into existing structures is more expensive than doing so at the outset. Long-term benefits may also differ, for example, if they ramp up slowly over time. Since implementation is delayed there are no short-term benefits.

Bringing the response measure forward makes sense if NPVnow is greater than $N P V$ later. That is, if NPV now - NPVlater is greater than zero. So we subtract the second equation from the first and find:

$$
\left(\delta \cdot \text { Cost }^{\text {later }}-\text { Cost }^{\text {now }}\right)+S T_{-} \text {Benefit }^{\text {now }}+\left(\delta \cdot L T_{\text {Benefit }}{ }^{\text {now }}-\delta \cdot L T_{\text {Benefit }}^{\text {later }}\right)>0
$$

This gives us three generic factors that justify bringing resilience measures forward:

- If the capital cost of implementing the measure later is higher than doing so today, that is, if we risk lock-in into a costly development path.

- If a measure has substantial short-term benefits that would otherwise be forgone, that is, if it is a low-regret option.

- If a delay would reduce future benefits, for example, because they would not materialize in time due to long lead-times. 
time horizon of perhaps five to ten years, although they influence development paths and climate vulnerability over several decades. Over a fiveto ten-year time horizon, there are numerous development, investment and planning decisions that meet one of the above criteria for priority adaptation.

In terms of low-regrets options, interventions that yield both development and climate-resilience benefits relate, for example, to human development, environmental protection and rural development. There is an urgent need to improve agricultural productivity and reform the institutional environment in terms of land titling, water abstraction and water management, as Mintewab Bezabih, Stefania Lovo and co-authors discuss in Chapter 9. Another promising option with immediate benefits is risk sharing and insurance, reviewed by Swenja Surminski in Chapter 10. There is a long tradition of managing risks by spreading them across larger population groups, and a lack of post-disaster finance for reconstruction is known to aggravate and prolong a crisis (World Bank, 2010). However, formal insurance schemes in developing countries are still rare.

There is also a large number of development interventions that have long-term consequences for climate resilience. Much of the basic infrastructure in developing countries is yet to be built. There is a huge need to invest in roads, railway lines, ports, airports, electric power systems and water supply networks. Urban areas are also developing rapidly. The point in time when new urban centres are planned and large-scale infrastructure is built is a natural 'entry point' for adaptation. In Chapter 5 Simon Dietz, Charlie Dixon and John Ward review the infrastructure deficits and plans in sub-Saharan Africa with a view to identify future adaptation hot spots. In Chapter 8, Hélia Costa, Graham Floater and Jared Finnegan discuss the particular challenges of climate-resilient urban development.

The identification of generic adaptation priorities and 'hot spots' for intervention does not obviate the need for careful project appraisal. Resilience measures can easily be mis-specified. In Chapter 6, Paul Watkiss and Alistair Hunt discuss the analytical challenges that this may raise, in particular in dealing with climate uncertainty. While the basic processes that drive climate change are well understood, the exact nature of future climatic changes at particular locations remains highly uncertain. In designing adaptation responses, the right combination between robustness and flexibility must therefore be found to prepare for different possible climate outcomes.

It is worth emphasizing that climate uncertainty does not imply a waitand-see approach to climate resilience. For one thing, the prospects for improvements in our ability to forecast climate changes at a fine spatial resolution appear dim (Stainforth et al., 2007; Heal and Millner, 2014), 
which limit the value of waiting for new information. Moreover, in the case where adaptation policy might avoid locking in long-term exposure to climate risk the presence of uncertainty favours the early adoption of adaptation measures, under a precautionary principle (McDermott, 2016).

\subsection{TRANSFORMATIONAL CHANGE}

As Paul Watkiss observes in Chapter 6, most climate-resilient development plans currently aim to protect existing locations and activities through in situ adaptation, perhaps because their primary concern is moderate climate change. There is an argument that more attention should perhaps be paid to transformational adaptation.

Current adaptation strategies tend to be overly static (Kocornik-Mina and Fankhauser, 2015). They are geared at preserving current economic structures, for example, by putting a heavy emphasis on maintaining agricultural output, even though rural economies are evolving fast. After an extreme event, there is a temptation to rebuild the economy 'just as it was before', rather than factoring in manifest climate risks. Even analytically, climate change impact assessments often impose climate change on today's economy, rather than the socio-economic structures of the future.

Climate-resilient development is inherently more dynamic. It recognizes that even before climate change many developing countries are undergoing a process of deep socio-economic change. Factors like economic growth, population growth, technological innovation, globalization and urbanization are combining to alter the fabric of developing economies. Strategies for climate resilience have to recognize and leverage these trends, rather than trying to stem them. In other words, adaptation to climate change has to become more transformational.

Resilience measures are considered to be transformational if at least one of three conditions holds: (1) the measures are pursued at a large scale; (2) they rely on novel approaches and tools; or (3) they involve deep structural changes to economic activity and/or location (Kates et al., 2012). The classification makes it clear that transformational adaptation is not without friction. Even if it leverages existing trends, there may be rigidities and path dependencies that are hard to overcome. The successful implementation of transformational change is therefore as much about the political economy as it is about development planning.

The transformational adaptation response where this is most manifest is relocation. Migration away from hazard zones is a well-established and common coping strategy in many countries, as Maria Waldinger shows in Chapter 11. However, such migration is often temporary and in most 
cases domestic. International migration caused directly by climate shocks is rare. Even so, Chapter 11 makes clear the large degree of institutional safeguards that are needed, both in the sending and the receiving jurisdiction, to make migration an effective adaptation tool. Unplanned and uncoordinated migration, quite possibly from one hazard zone into another, is more likely to be a sign of adaptation failure.

\subsection{CONCLUSIONS}

Climate-resilient development integrates development policy with adaptation to climate change. The integration is sensible, given the multiple links between the two concerns. A certain amount of climate change is now unavoidable and developing countries are likely to be most affected by it. But there is also an opportunity to reduce future vulnerability by guiding growth and development in a climate-resilient direction.

Policy makers must become aware of the consequences for climate vulnerability of development choices, and identify 'entry points' for adaptation action; that is, opportunities to incorporate climate resilience into long-term development, infrastructure and spatial planning decisions. This is likely to reveal trade-offs - for example, between urban growth and climate vulnerability - but well-designed projects will also be able to exploit synergies between climate resilience, growth and poverty alleviation.

Pursuing climate-resilient development has implications for both adaptation and development policy (Kocornik-Mina and Fankhauser, 2015). It forces development planners and adaptation planners to work more closely together. In the process, economic development plans will become more climate-aware and acknowledge future climate risks. In turn, adaptation plans may begin to reflect better the dynamism and evolving nature of modern economies, perhaps leading to more transformative forms of adaptation.

There are also institutional consequences. Climate-resilient development shifts the responsibility for adaptation from environment departments and hydro-meteorological offices to planning and economic ministries. These tend to be more powerful and better able to instigate the necessary reforms. It is an important and sometimes overlooked side-effect of moving from adaptation to climate-resilient development.

\section{REFERENCES}

ASC, 2014. Managing Climate Risks to Wellbeing and the Economy. Progress Report 2014. London: UK Adaptation Sub-Committee. 
Bowen, A. and Hepburn, C., 2014. 'Green growth: an assessment', Oxford Review of Economic Policy, 30(3), 407-22.

Bowen, A., Cochrane, S. and Fankhauser, S., 2012. 'Climate change, adaptation and growth', Climatic Change, 113(2), 95-106.

Brooks, N., Adger, W.N. and Kelly, P.M., 2005. 'The determinants of vulnerability and adaptive capacity at the national level and the implications for adaptation', Global Environmental Change, 15(2), 151-63.

Callaway, J.M., Louw, D.B., Nkomo, J.C., Hellmuth, M.E. and Sparks, D.A., 2006. 'The Berg river dynamic spatial equilibrium model: a new tool for assessing the benefits and costs of alternatives for coping with water demand growth, climate variability, and climate change in the Western Cape', Document de travail de l'AIACC No. 31, 41.

Cimato, F. and M. Mullan, 2010. 'Adapting to climate change: analysing the role of government', Defra Evidence and Analysis Series, Paper 1, UK Department for the Environment, Food and Rural Affairs, London.

Dell, M., Jones, B. and Olken, B., 2012. 'Temperature shocks and economic growth: evidence from the last half a century', American Economic Journal: Macroeconomics, 4(3), 66-95.

Fankhauser, S., 2010. 'The costs of adaptation', Wiley Interdisciplinary Review Climate Change, 1(1), 23-30.

Fankhauser, S. and McDermott, T.K.J., 2014. 'Understanding the adaptation deficit: why are poor countries more vulnerable to climate events than rich countries?', Global Environmental Change, 27, 9-18.

Fankhauser, S. and Tol, R.S.J., 2005. 'On climate change and economic growth', Resource and Energy Economics, 27(1), 1-17.

Fankhauser, S., Smith, J.B. and Tol, R., 1999. 'Weathering climate change. some simple rules to guide adaptation investments', Ecological Economics, 30(1), 67-78.

Füssel, H.M. 2007. 'Adaptation planning for climate change: concepts, assessment approaches, and key lessons', Sustainability Science, 2(2), 265-75.

Hallegatte, S., Lecocq, F. and de Perthuis, C. 2011. 'Designing climate change adaptation policies. an economic framework', Policy Research Working Paper No. 5568, World Bank, Washington, DC.

Hallegatte, S., Shah, A., Brown, C., Lempert, R. and Gill, S., 2012. 'Investment decision making under deep uncertainty - application to climate change', Policy Research Working Paper No. 6193, World Bank, Washington, DC.

Hanson, S., Nicholls, R., Ranger, N. et al., 2011. 'A global ranking of port cities with high exposure to climate extremes', Climatic Change, 104(1), 89-111.

Heal, G. and Millner, A., 2014. 'Uncertainty and decision making in climate change economics', Review of Environmental Economics and Policy, 8(1), 120-37.

IPCC, 2014. Climate Change 2014: Impacts, Adaptation, and Vulnerability. Contribution of Working Group II to the Fifth Assessment Report of the Intergovernmental Panel on Climate Change. Cambridge: Cambridge University Press.

Kahn, M., 2005. 'The death toll from natural disasters: the role of income, geography, and institutions', Review of Economics and Statistics, 87(2), 271-84.

Kates, R.W., Travis, W.R. and Wilbanks, T.J., 2012. 'Transformational adaptation when incremental adaptations to climate change are insufficient', Proceedings of the National Academy of Sciences, 109(19), 7156-61.

Kocornik-Mina. A. and Fankhauser, S., 2015. 'Climate change adaptation in 
dynamic economies', Policy Brief, Grantham Research Institute on Climate Change, London School of Economics.

McDermott, T.K.J., 2016. 'Investing in disaster risk management in an uncertain climate', World Bank Policy

Research Working Paper, No WPS7631. World Bank: Washington DC.

McDermott, T.K.J., Barry, F. and Tol, R.S.J., 2014. 'Disasters and development: natural disasters, credit constraints and economic growth', Oxford Economic Papers, 66(3), 750-73.

McGray, H., Hamill, A., Bradley, R., Schipper, E.L. and Parry, J.-O., 2007. Weathering the Storm. Options for Framing Adaptation and Development. Washington, DC: World Resources Institute.

Mendelsohn, R., Nordhaus, W. and Shaw, D., 1994. 'The impact of global warming on agriculture: a Ricardian analysis', American Economic Review, 84(4), 753-71.

Pearce, D., Markandya, A. and Barbier, E., 1989. Blueprint for a Green Economy. London: Earthscan.

Ranger, N., Millner, A., Dietz, S., Fankhauser, S., Lopez, A. and Ruta, G., 2010. 'Adaptation in the UK: a decision-making process', Policy Brief, Grantham Research Institute on Climate Change and the Environment, London School of Economics.

Repetto, R., 2008. 'The climate crisis and the adaptation myth', Working Paper No. 13, Yale School of Forestry and Environmental Studies.

Schelling, T., 1992. 'Some economics of global warming', American Economic Review, 82(1), 1-14.

Schelling, T., 1997. 'The cost of combating global warming: facing the tradeoffs', Foreign Affairs, 76(6), 8-14.

Schneider, S.H., Easterling, W.E., and Mearns, L.O., 2000. 'Adaptation: sensitivity to natural variability, agent assumptions and dynamic climate changes', Climatic Change, 45(1), 203-21.

Stainforth, D., Allen, M., Tredger, E. and Smith, L., 2007. 'Confidence, uncertainty and decision-support relevance in climate predictions', Philosophical Transactions of the Royal Society A: Mathematical, Physical and Engineering Sciences, 365(1857), 2145-61.

Stern, N., 2015. Why are We Waiting? The Logic, Urgency and Promise of Tackling Climate Change. Cambridge, MA: MIT Press.

Tol, R. and Yohe, G., 2007. 'The weakest link hypothesis for adaptive capacity: an empirical test', Global Environmental Change, 17, 218-27.

Vivid Economics, 2015. Understanding Patterns of Climate-resilient Economic Development: Synthesis Report, Report for the UK Department for International Development, London.

World Bank, 2010. World Development Report 2010: Development and Climate Change. Washington, DC: World Bank Group. 
Sam Fankhauser and Thomas K.J. McDermott - 9781785360312 Downloaded from PubFactory at 04/26/2023 10:23:11AM via free access 